\title{
A cross-sectional study to assess an association between upper extremity function and functional walking capacity in chronic stroke survivors
}

Ameerani Jarbandhan ${ }^{*}$ (1); Jerry Toelsie ${ }^{2}$ (D); Robbert Bipat ${ }^{2}$ (D); Jeannine Freedrik ${ }^{1}$ (1); Luc Vanhees $^{3}$ (1); Roselien Buys ${ }^{3}$ (D) ; DirkJan H.E.J. Veeger ${ }^{4}$ (1)

\begin{abstract}
Background: The Six-Minute Walk Test (6MWT) predicts community ambulation in stroke patients. These patients frequently face several disabilities, including upper extremity dysfunction. Since upper extremity (UE) dysfunction is related to walking disability, we expect that the UE function is associated with the 6MWT. So far, no study has directly investigated the association between UE function and the 6MWT. Aims: To examine the association between UE function and the 6MWT in stroke survivors adjusted for balance and gait problems. Methods: Subjects were randomly recruited from the general population and the Academic Hospital Paramaribo. UE function was measured using the handgrip strength (HGS) test, Disabilities of the Arm Shoulder and Hand (DASH) survey and Stroke Impact Scale (SIS) survey. Functional walking capacity was measured by the 6MWT. Functional balance was measured using the Berg Balance Scale (BBS). Step length ratio (SLR) and step width (SW) were used to assess gait. The median (range) or mean \pm SD are presented. Results: In fifty subjects with a mean age of $58.2 \pm 9.5$ years, we demonstrated that the mean 6MWT $(297.9 \pm 19.8 \mathrm{~m})$ correlated with the mean paretic HGS $(19.1 \pm 14.9 \mathrm{~kg}, r=0.77, p<0.001)$ and non-paretic HGS $(31.1 \pm 9.7 \mathrm{~kg}, r=0.41, p=0.003)$, but not with the DASH and SIS surveys. The 6MWT correlated with the BBS (55.0(30.0-56.0), $r=0.51, p<0.001)$, SLR (0.9(1.0-2.0), $r=-0.29, p=0.044)$, but did not correlate with SW. After adjusting for BBS and SLR, paretic HGS explained $62 \%$ of the variance in $6 \mathrm{MWT}$. The relationship between non-paretic HGS and 6MWT was influenced by the BBS and SLR $(p<0.05$, $\mathrm{R}^{2}=0.39$ ). Conclusions: Paretic handgrip strength predicts $6 \mathrm{MWT}$ performance after adjusting for balance and gait asymmetry. The 6MWT is limited by stroke-related impairments such as handgrip strength, balance control and gait asymmetry. Further studies are warranted for assessment of causal effects between these variables.
\end{abstract}

Keywords: Upper extremity; Six-minute walk test; Cerebrovascular stroke; Handgrip strength.

${ }^{1}$ Anton de Kom University of Suriname, Dept. of Anatomy, Paramaribo, Suriname

${ }^{2}$ Anton de Kom University of Suriname, Dept. of Physiology, Paramaribo, Suriname ${ }^{3}$ Katholieke Universiteit Leuven - KU Leuven, Dept. of Rehabilitation Sciences, Leuven, Belgium

${ }^{4}$ Dept. of Biomechanical Engineering, Delft University of Technology, Delft, The Netherlands

\section{*Corresponding author: Ameerani Jarbandhan \\ Kernkampweg 5, Paramaribo, Suriname Phone: +597 8654770 \\ Email: ameerani.jarbandhan@uvs.edu}

Submitted: March 19, 2021.

Accepted: September 07, 2021.

Study conducted at: The Faculty of Medical

Sciences (FMeW), Parmaribo, Suriname.

Ethical approval number: VG-023-15

Ethical approval Committee: CMWO

(Commissie Mensgebonden Wetenschappelijk Onderzoek) at the Government of Suriname's, Ministry of Health.

\section{How to cite}

Jarbandhan A, Toelsie J, Bipat R, Freedrik J, Vanhees L, Buys R, et al. A cross-sectional study to assess an association between upper extremity function and functional walking capacity in chronic stroke survivors. Cardiorespir Physiother Crit Care Rehabil. 2021;1:e42992. https://doi.org/10.4322/2675-9977.cpcr.42992

\section{How can the results of this study be used in clinical practice?}

- Paretic handgrip strength is associated to the 6MWT after adjusting for balance control and gait asymmetry.

- The relationship between non-paretic handgrip strength and the 6MWT is influenced by balance control and gait asymmetry.

- No association was found between patient-reported (paretic) UE function and the 6MWT. 


\section{Introduction}

In post stroke survivors, the six-minute walk test (6MWT) is frequently used to measure functional walking capacity, which can be defined as the extent to which increased intensities of walking capacity can be maintained to perform activities of daily living (ADL) $)^{1,2}$. This test is considered as a valid, reliable and feasible tool to measure functional walking capacity in post-stroke patients ${ }^{1}$, is well tolerated, easy to use and it better reflects ADL than other walking tests ${ }^{1,3}$. The 6MWT is also an independent predictor for community ambulation and an indicator for post-stroke recovery ${ }^{4,5}$. However, this test embraces a complex interaction with several stroke related factors ${ }^{3}$. It is known that it is influenced by several stroke-related impairments such as energy cost of walking $^{6}$, gait asymmetry ${ }^{7}$ and balance impairments ${ }^{8}$.

Growing evidence suggest that the upper extremity (UE) function affects the walking capacity in stroke patients. Stroke survivors suffer frequently from disabilities, like motor deficits in the extremities, which impedes proper community ambulation (defined as the ability of a person to walk in their own community) ${ }^{9}$. It is suggested that the cycling motion of the UE serves to reduce energy cost during bipedal human gait $^{10}$. In addition, arm cycling training improved post-stroke walking ability ${ }^{11}$ and a coordination between the upper and contralateral lower limb during walking is demonstrated in post-stroke survivors ${ }^{12}$. Moreover, immobilization of the UE induced negative changes in spatial gait parameters ${ }^{13}$ and the handgrip strength (part of UE function) was associated to walking in elderly ${ }^{14}$ and patients with lumbar stenosis ${ }^{15}$. Since these studies suggest that the UE function affects the walking capacity, we expect that the UE function might also affect the $6 \mathrm{MWT}$. So far, only one study ${ }^{16}$ reported a moderate correlation between the 6MWT and the Stroke Impact Scale (SIS) hand function domain in 30 chronic stroke survivors.

Therefore, this study aimed to assess the association between UE function, as assessed by objective and patientreported outcome measures, and the 6MWT after adjustment for balance control and gait asymmetry. We hypothesize that there is a positive association between UE function and the 6MWT performance.

\section{Methods}

\section{Participants}

Participants were recruited from the database of the Academic Hospital of Paramaribo, as well as respondents from the general population, in the period of April 2016 to April 2017. The participants had to meet the following criteria of respective assessment tools in order to participate in this study: (i) be able to give informed consent and understand simple instructions (Mini Mental Scale Examination >24); (ii) had a stroke at least six months prior; (iii) be able to walk at least $10 \mathrm{~m}$ independently or without supervision (Functional Ambulation Category score $\geq 3$ ), (iv) age above twenty-five years; and (v) living at home. Stroke patients who had (i) a serious cardiac condition, (ii) other serious end organ damage, (iii) other neurological deficits or (iv) uncontrolled blood pressure (systolic pressure $>140 \mathrm{mmHg}$, diastolic pressure $>90 \mathrm{mmHg}$ ), were excluded. All participants gave informed consent, and approval was received from the Institutional Review Board (CMWO: Commissie Mensgebonden Wetenschappelijk Onderzoek) at the Government of Suriname's, Ministry of Health (reference number: VG023-15).

\section{Anthropometric and sociodemographic data}

Demographic (sex; age; ethnicity), anthropometric (Body Mass Index (BMI)) and clinical (type of stroke; recurrent stroke; time since stroke; affected side, hand dominance) data were recorded. Ethnicity was self-reported and further divided into Asian (Hindustani and/or Javanese), African (Creole and/ or Maroon) and other. BMI was calculated based on weight and height $\left(\mathrm{kg} / \mathrm{m}^{2}\right)$.

\section{Upper extremity function}

Handgrip strength was measured using a hand dynamometer with an adjustable handle (Suahan Digital, Korea). The upper arm was supported next to the body, with the elbow in 90 degrees of flexion, forearm in neutral position and wrist in slight extension ${ }^{17}$. The test for maximum handgrip strength was then performed three times for each hand, alternating between the non-paretic (HGNP) and paretic hand (HGP) with resting periods of 30 seconds. The highest value for each hand was used for analysis.

The DASH questionnaire ${ }^{18}$ is a 30 -item self-report questionnaire, with a score ranging from 0 (no disability) to 100 . Its main objective is to assess physical function, symptoms, social indicators and therefore encompasses the entire UE. Higher DASH scores indicate an increase in the severity of a disability.

The SIS version $3.0^{19}$ is a stroke-specific questionnaire used to evaluate stroke outcomes in eight domains. This study used the hand function domain only. The questions ascertained the level of exertion or difficulty to carry heavy objects, turning a doorknob, opening a can or jar, tying a shoelace, and picking up a dime. The scoring method is rated using a 5-point ordinal scale (1-5) for each item: $1=$ an inability to complete the item; $5=$ no difficulty at all. Domain scores range from $0-100$.

\section{Functional walking capacity}

The 6MWT participants were instructed to walk continuously at the fastest pace for 6 minutes on a ellipsoid (30-meter) pathway, as far as they could ${ }^{3}$. All participants received the same standardized instructions and encouragement and were allowed to use assistive devices such as a cane ${ }^{3}$. The maximum distance covered in six minutes was recorded in meters $^{3}$. 


\section{Gait Analysis}

Spatial gait parameters such as step length and step width were determined using a double 2-D functional gait assessment. Participant's movements were video recorded while walking with their preferred walking velocity on a 10-meter pathway. Two cameras (Sony and Panasonic Hand-Held Camcorder) were strategically placed for ventral/ dorsal and lateral view. All the participants walked back and forth twice. Kinovea 8.15 , was used to extract frames and coordinates from these videos ${ }^{20}$ and three extracted frames were used to calculate step length and step width. Step width was measured using frames with a dorsal view, during the double stance phase. Step length was measured using the average of three frames from the lateral view ${ }^{20}$, during the subject's double stance phase, from the heel of the non-paretic foot to the heel of the paretic foot. In case one heel was not in contact with the ground (e.g., drop foot), the measure was done from the head of the first metatarsal of the paretic foot to the head of the first metatarsal of the non-paretic foot. Data from the step length were used to assess step length asymmetry (or gait asymmetry).

Gait asymmetry was referred to as the Step Length Ratio (SLR) which was calculated as the ratio of the paretic step length relative to the non-paretic step length ${ }^{21}$. Step Width (SW) was measured as the distance between the left and right heel at mid stance. To correct for depth error in our video analysis a normalization procedure was performed for each subject in which step width and step length were corrected for the visible width of the walkway.

\section{Balance assessment}

The Berg Balance Scale (BBS) was used to evaluate balance and consists of 14 items in which the participant has to maintain different functional static positions, be able to move the Center of Mass and change the base of support without losing balance. The scoring method is a 5-point ordinal scale (0-4) for each item, with the total score ranging from $0-56^{22}$. A total BBS score lower than 29 indicates that the person is at risk for falls, whereas a score above 30 indicates functional balance. The test-retest agreements for use of the BBS in chronic stroke patients is high $(\mathrm{ICC} 2,1$ : BBS $=0.98)$, indicating excellent agreement from a relative perspective ${ }^{22}$.

\section{Statistical analysis}

All statistical analyses were performed using IBM SPSS version 23.0. The Shapiro-Wilk and Kolmogorov-Smirnov tests were used to test normal distribution of the residual values $^{23}$ of the dependent variable (the $6 \mathrm{MWT}$ ). The Spearman Rho test was used to study the association of UE function variables and functional walking capacity. Linear regression was used to assess associations between UE function and the 6MWT with models that adjusted for sex and age and subsequently, for balance control and gait problems known to be associated to the 6MWT. For all statistical analyses the level of significance was set at $\mathrm{p}<0.05$. We considered an $r \leq 0.3$ a weak correlation, an $r$ between 0.4 and 0.6 as a moderate correlation and high when $r \geq 0.7^{24}$.

\section{Results}

\section{Participants}

Figure 1 shows the participant flow. From 777 contact details, the telephone numbers of only 530 patients were in use. From these patients, sixty-seven refused participation, 413 did not meet the criteria, therefore, fifty participants were included in this study. There was no missing data. Participants or their physicians were called in order to evaluate eligibility for the $6 \mathrm{MWT}$ according to the inclusion and exclusion criteria. The characteristics of these 50 participants can be found in Table 1.

Data for the 6MWT show a normal distribution. The mean \pm SD 6MWT was $297.9 \pm 19.8 \mathrm{~m}$. Table 2 shows the correlation between the 6MWT and the UE function parameters as well as the BBS and gait parameters. The 6MWT correlated with paretic and non-paretic handgrip strength (Figure 2). The strongest correlation is with paretic handgrip strength $(\mathrm{r}=0.77)$ followed by a moderate correlation with the non-paretic handgrip strength $(\mathrm{r}=0.41)$ (Figure 2). The scores from the two UE function surveys, DASH and SIS (hand function domain), did not correlate with the 6MWT. Moreover, the BBS and SLR correlated with the 6MWT, but SW did not.

No influence of sex and age was found regarding the relationship between HGS and the 6MWT (Table 3). HGP explained $62 \%$ of the variance in $6 \mathrm{MWT}$ without significant contribution of the BBS and SLR (Table 3). The BBS and SLR significantly influenced the relationship between HGNP

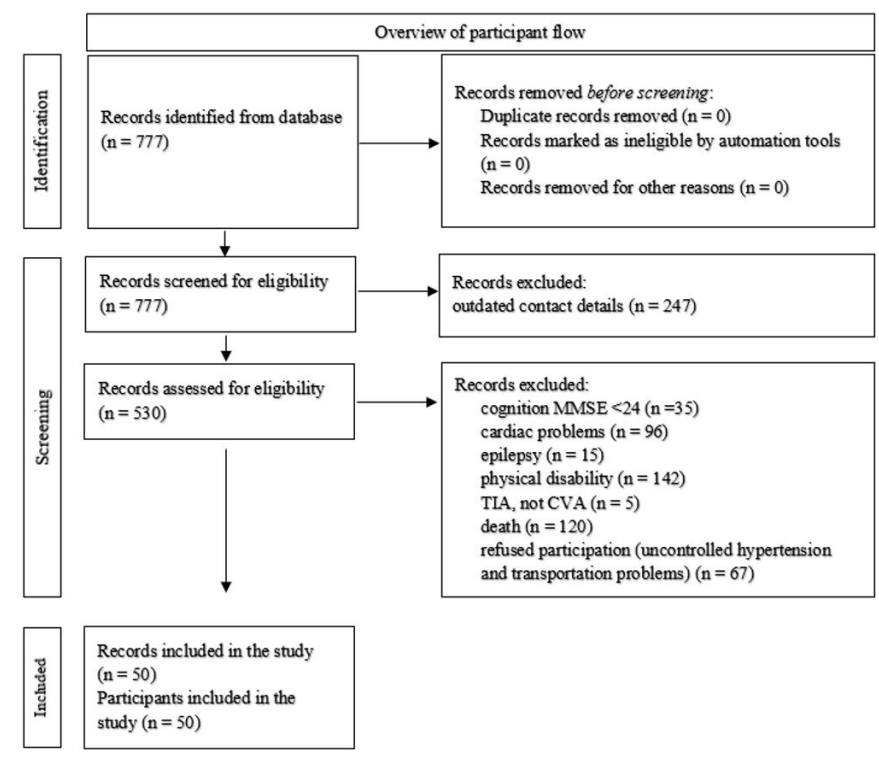

Figure 1. Overview of participant flow. CVA: CerebroVascular Accident; MMSE: Mini Mental State Examination; TIA: Transient Ischemic Attack. 
and the 6MWT and these parameters explained $39 \%$ of the variance in the 6MWT (Table 3).

\section{Discussion}

We examined the association between UE function and the 6MWT in chronic stroke survivors adjusted for balance impairment and gait problems. HGP and HGNP correlated with the 6MWT. In contrast, no association was found with the DASH and the SIS (hand function domain). HGP independently explained $62 \%$ of the variance in the $6 \mathrm{MWT}$, whereas the relationship between HGNP and the 6MWT was influenced by the BBS and SLR.

The observed relationship between handgrip strength and the 6MWT in elderly and lumbar stenosis patients is now

Table 1. Sociodemographic, anthropometric and clinical characteristics of all participants.

\begin{tabular}{lc}
\hline \multicolumn{1}{c}{ Variables ( $\mathbf{N}=\mathbf{5 0}$ participants) } & Value/number \\
\hline Age (years, mean $\pm \mathrm{SD})$ & $58.2 \pm 9.5$ \\
Sex (males) $(\mathrm{N})$ & 24.0 \\
Time since stroke (years, median (range) & $2.6(0.5-16.6)$ \\
Recurrent stroke (N, yes) & 12.0 \\
Type of Stroke (N, ischemic) & 46.0 \\
Dominant side affected (N, yes) & 23.0 \\
Location stroke (N, right hemisphere) & 27.0 \\
BMI (kg/m ${ }^{2}$, median (range)) & $26.4(19.6-39.6)$ \\
Ethnicity (N) & \\
Asian descent & 28.0 \\
African descent & 16.0 \\
Other & 6.0 \\
\hline
\end{tabular}

BMI: Body Mass Index. also observed in stroke patients, despite their overall loss of muscular strength after a stroke ${ }^{25}$. However, compared to older adults our study population showed an overall lower level of 6MWT and handgrip strength ${ }^{26}$. While the HGS is a form of isotonic contraction, the 6MWT is more appealing to concentric and eccentric forms of muscle contraction over a relatively longer period of time compared to the HGS test. However, both appear to be associated to other muscle groups of the body ${ }^{27,28}$. It might therefore be argued that both represent overall muscle strength of the body, which is often decreased after stroke ${ }^{25}$. This might be an explanation for the correlation that we showed between paretic HGS and reduced 6MWT performance after adjusting for the BBS and SLR, however it does not explain the relationship between non-paretic handgrip strength and the 6MWT. Due to the variety in the level of non-paretic handgrip strength in our study population it cannot be assumed that the relationship with the 6MWT is due to common aetiology of stroke.

Hemiparetic gait is usually characterized by several compensation strategies ${ }^{29}$ that serve to, not only guarantee safe ambulation ${ }^{30}$, but also reduce increased mechanical cost of gait after stroke. These compensation strategies (i.e., excessive arm swing during increased walking speed ${ }^{31}$, gait asymmetry or increased stepwidth) may differ in various situations. For example, during the 6MWT, in which walking speed is self-paced but exertion of maximum effort is encouraged for a relatively prolonged period, it is demonstrated that stroke-related impairments such as balance control and lower limb motor score limit the outcome measure in post-stroke survivors ${ }^{7}$. This might also explain why the relationship between the non-paretic HGS, associated to the ipsilateral muscle strength in post-stroke survivors ${ }^{32}$, and the 6MWT was influenced by the BBS and SLR. Consequently, it might be argued that compensation strategies are reflected by the handgrip strength, balance control and gait asymmetry during the performance of the 6MWT due to (neuro)muscular fatigue mechanisms ${ }^{7,8,33}$. Moreover, we also demonstrated a

Table 2. Correlation with functional walking capacity (6MWT, N=50).

\begin{tabular}{lccc}
\hline \multicolumn{1}{c}{ UE function parameters } & Mean (SE) & Correlation coefficient (r) & p-value (two-tailed) \\
\hline HGP $(\mathrm{kg})^{\wedge}$ & $19.1(2.1)$ & 0.76 & 0.000 \\
HGNP $(\mathrm{kg})$ & $31.1(1.3)$ & 0.41 & 0.003 \\
DASH score (0-100) & $32.9(3.8)$ & -0.26 & 0.062 \\
SIS (hand function domain) score (0-100) & $54(3.8)$ & 0.24 & 0.085 \\
Balance and gait parameters & & & 0.000 \\
BBS** & $52.30(0.87)$ & 0.51 & 0.044 \\
SLR & $1.02(0.03)$ & -0.28 & 0.057 \\
SW & $13.42(0.78)$ & -0.27 & \\
\hline
\end{tabular}

6MWT: Six-minute walk test; BBS: Berg Balance Scale. DASH: Disabilities of the Arm, Shoulder and Hand; HGNP: Handgrip Strength Non-Paretic; HGP: Handgrip Strength Paretic; SIS: Stroke Impact Scale; SLR: Step Length Ratio; SW: Step Width. **BBS is correlated with SW ( $\mathrm{r}=-0.291, \mathrm{p}=0.041$ ). ${ }^{*} \mathrm{HGP}$ is correlated with HGNP ( $\mathrm{r}=0.54$, $\mathrm{p}=0.000)$; DASH $(\mathrm{r}=-0.41, \mathrm{p}=0.003)$; SIS hand function domain $(\mathrm{r}=0.45, \mathrm{p}=0.001)$. 

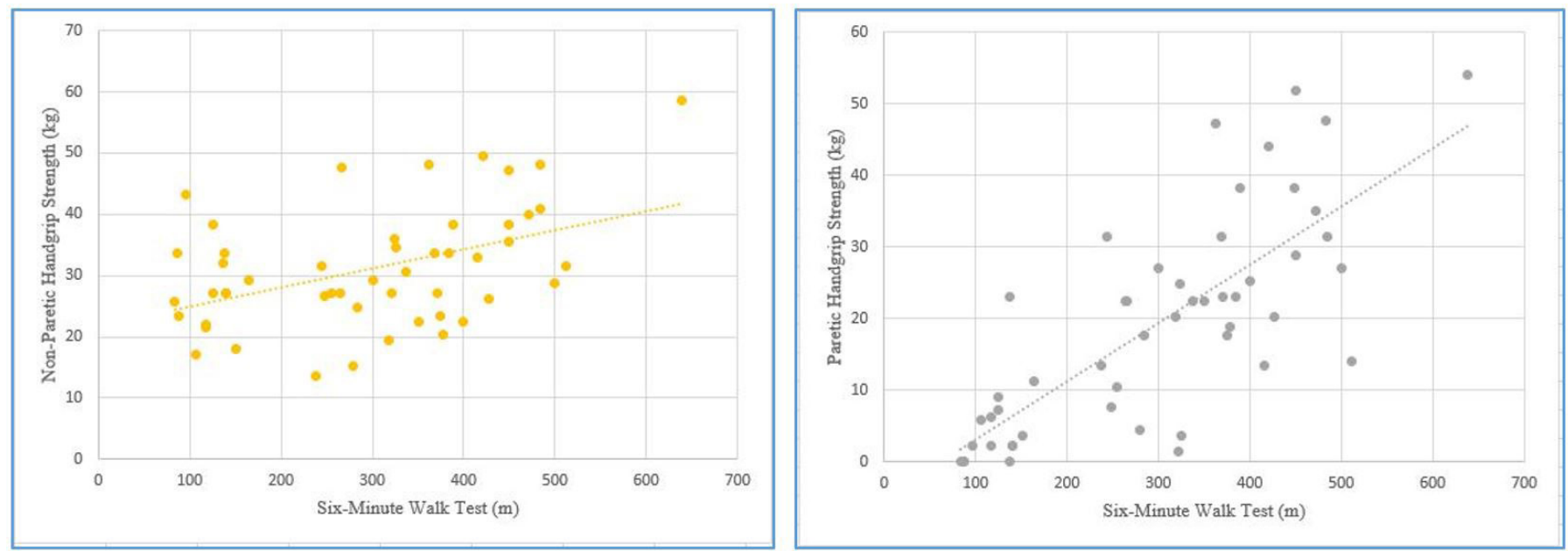

Figure 2. Scatterplots of handgrip strength related to functional walking capacity.

Table 3. Regression analysis between handgrip strength and functional walking capacity.

\begin{tabular}{|c|c|c|c|c|}
\hline \multirow{2}{*}{$\begin{array}{l}\text { Functional walking } \\
\text { capacity }\end{array}$} & \multicolumn{4}{|c|}{ HGP(kg) } \\
\hline & Unstandardized coefficients & Standard error & p-value & R-square \\
\hline Model 1: (constant) & 147.8 & 93 & 0.119 & 0.59 \\
\hline HGP & 7.2 & 0.9 & 0 & \\
\hline Sex & 2.5 & 27.7 & 0.927 & \\
\hline Age & 0.1 & 1.4 & 0.911 & \\
\hline Model 2: (constant) & 66.1 & 135.6 & 0.628 & 0.62 \\
\hline HGP & 6.3 & 0.9 & 0 & \\
\hline BBS & 3.5 & 2.2 & 0.12 & \\
\hline \multirow[t]{2}{*}{ SLR } & -73.3 & 58 & 0.213 & \\
\hline & \multicolumn{4}{|c|}{ HGNP(kg) } \\
\hline Model 1: (constant) & 218.5 & 140.9 & 0.128 & 0.21 \\
\hline HGNP & 6.2 & 2.1 & 0.005 & \\
\hline Sex & -1.8 & 1.9 & 0.331 & \\
\hline Age & -9.7 & 40.6 & 0.811 & \\
\hline Model 2: (constant) & -38.2 & 172.5 & 0.826 & 0.39 \\
\hline HGNP & 5.7 & 1.7 & 0.001 & \\
\hline BBS & -177.3 & 72.6 & 0.019 & \\
\hline SLR & 6.4 & 2.7 & 0.022 & \\
\hline
\end{tabular}

BBS: Berg Balance Scale. HGNP: Handgrip Strength Non-Paretic; HGP: Handgrip Strength Paretic; SLR: Step Length Ratio.

relationship between paretic and non-paretic HGS, therefore, it might be suggested that the non-paretic HGS is indeed important to compensate for the affected upper limb ${ }^{32}$ during bi-manual activities as well as forward movement of the body ${ }^{12}$.

Furthermore, we demonstrated no association between functional walking capacity and paretic UE function quantified by the DASH and the SIS (hand function domain). We did not expect this, but a possible explanation might be that compared to handgrip tests, these surveys take more items such as fine UE motor skills, environmental and social items into account ${ }^{18,19}$. In contrast to our study, the study by Muren et al. ${ }^{16}$ in stroke survivors showed a positive correlation between the SIS (hand function domain) and the 6MWT. Compared to our study, the variation in sample size, BMI score and level of functional walking capacity are factors that might be responsible for these discrepancies. Additionally, we found a correlation between the paretic HGS, the DASH 
and the SIS (hand function domain) in our study population, which can be explained by the fact the handgrip strength reflects $\mathrm{ADL}^{34}$ as well as the general muscle fitness ${ }^{27,28}$ of a stroke patient during performance of the test. Similarly, in another study handgrip strength was negatively correlated to the DASH in cardiac patients ${ }^{35}$.

\section{Limitations}

It should be noted that all tests were conducted in the laboratory instead of the field or home-based setting ${ }^{36}$. The external environment has a significant impact on the quality of gait metrics ${ }^{36}$, and is considered more representative to real-life situations. It is advisable that the performance of the 6MWT is researched in a patient's home or a homebased setting. In our study we did not include a practice walk before executing the 6MWT. It is generally advised to have a practice walk before the real measurement of functional walking capacity to prevent a practice effect, but a study in sub-acute and chronic stroke survivors indicates that a practice walk is not needed ${ }^{37}$. So, we do not expect any bias due to the absence of a practice walk. All of our participants were able to finish a 6MWT, which suggests that the results of the present study cannot be generalized to all individuals with stroke. The general stroke population might be less fit or severely impaired compared to our study sample. In addition, we also needed to take into account that patient-reported outcome measures are prone to social desirability bias. Moreover, there is a lack of studies (solely two studies) ${ }^{38,39}$ validating the use of the DASH questionnaire for UE function in post-stroke patients, but our results show that the DASH correlated with the SIS hand function and handgrip strength. Therefore, we do not expect our results from the DASH to introduce any form of bias. The fact that we observed low levels of the HGS and 6MWT might also have resulted from our multi-ethnic population, as the majority of our study population was from an (South-)Asian background ${ }^{40,41}$, however due to an imbalance in the ethnic groups an adequate adjustment for this variable was not possible. Future studies should try to study effects of the multi-ethnic backgrounds in the relationship between these variables.

In conclusion, the association between paretic hand strength and functional walking capacity is stronger than the associations of non-paretic handgrip strength, sex, age, balance control, gait asymmetry and functional walking capacity. Further investigation is needed to assess whether handgrip strength can be used as a tool for intervention in order to improve walking capacity.

\section{Funding}

The authors have reported that no funding was received for this study.

\section{Conflict of interest}

None.

\section{References}

1. van Bloemendaal M, van de Water AT, van de Port IG. Walking tests for stroke survivors: a systematic review of their measurement properties. Disabil Rehabil. 2012;34(26):2207-21. http://dx.doi.org/10.3109/096 38288.2012.680649. PMid:22583082.

2. Kim DK, Oh DW. Repeated use of 6-min walk test with immediate knowledge of results for walking capacity in chronic stroke: clinical trial of fast versus slow walkers. J Stroke Cerebrovasc Dis. 2019;28(11):104337. http://dx.doi.org/10.1016/j. jstrokecerebrovasdis.2019.104337. PMid:31522886.

3. Dunn A, Marsden DL, Nugent E, Van Vliet P, Spratt NJ, Attia $\mathrm{J}$, et al. Protocol variations and six-minute walk test performance in stroke survivors: a systematic review with meta-analysis. Stroke Res Treat. 2015;2015:484813. http://dx.doi.org/10.1155/2015/484813. PMid:25685596.

4. Yi Y, Shim JS, Oh BM, Seo HG. Grip strength on the unaffected side as an independent predictor of functional improvement after stroke. Am J Phys Med Rehabil. 2017;96(9):616-20. http://dx.doi.org/10.1097/ PHM.0000000000000694. PMid:28085737.

5. Pratama IK, Setiati, S. Correlation between hand grip strength and functional mobility in elderly patients. In: IOP Publishing, editor. The 2nd Physics and Technologies in Medicne and Dentistry Symposium; 2018 July 18; Indonesia: IOP Publishing; 2018. (Journal of Physics: Conf. Series; vol. 1073, no. 4). http://dx.doi.org/10.1088/17426596/1073/4/042034.

6. Eng JJ, Dawson AS, Chu KS. Submaximal exercise in persons with stroke: test-retest reliability and concurrent validity with maximal oxygen consumption. Arch Phys Med Rehabil. 2004;85(1):113-8. http://dx.doi.org/10.1016/S0003-9993(03)00436-2. PMid:14970978.

7. Sibley KM, Tang A, Patterson KK, Brooks D, McIlroy WE. Changes in spatiotemporal gait variables over time during a test of functional capacity after stroke. J Neuroeng Rehabil. 2009;6(1):27. http://dx.doi. org/10.1186/1743-0003-6-27. PMid:19594945.

8. Pohl PS, Duncan PW, Perera S, Liu W, Lai SM, Studenski S, et al. Influence of stroke-related impairments on performance in 6-minute walk test. J Rehabil Res Dev. 2002;39(4):439-44. PMid:17638141.

9. Sall J, Eapen BC, Tran JE, Bowles AO, Bursaw A, Rodgers ME. The management of stroke rehabilitation: a synopsis of the 2019 U.S. Department of Veterans Affairs and U.S. Department of Defense Clinical Practice Guideline. Ann Intern Med. 2019;171(12):916-24. http://dx.doi.org/10.7326/M19-1695. PMid:31739317.

10. Meyns P, Bruijn SM, Duysens J. The how and why of arm swing during human walking. Gait Posture. 2013;38(4):555-62. http://dx.doi. org/10.1016/j.gaitpost.2013.02.006. PMid:23489950.

11. Kaupp C, Pearcey GEP, Klarner T, Sun Y, Cullen H, Barss $\mathrm{TS}$, et al. Rhythmic arm cycling training improves walking and neurophysiological integrity in chronic stroke: the arms can give legs a helping hand in rehabilitation. J Neurophysiol. 2018;119(3):1095-112. http://dx.doi.org/10.1152/jn.00570.2017. PMid:29212917.

12. Bovonsunthonchai S, Hiengkaew V, Vachalathiti R, Vongsirinavarat M, Tretriluxana J. Effect of speed on the upper and contralateral lower limb coordination during gait in individuals with stroke. Kaohsiung J Med Sci. 2012;28(12):667-72. http://dx.doi.org/10.1016/j. kjms.2012.04.036. PMid:23217359.

13. Hong SH, Jung SY, Oh HK, Lee SH, Woo YK. Effects of the immobilization of the upper extremities on spatiotemporal gait parameters during walking in stroke patients: a preliminary study. BioMed Res Int. 2020;2020:6157231. http://dx.doi. org/10.1155/2020/6157231. PMid:32596338.

14. Savino E, Martini E, Lauretani F, Pioli G, Zagatti AM, Frondini $\mathrm{C}$, et al. Handgrip strength predicts persistent walking recovery after hip fracture surgery. Am J Med. 2013;126(12):1068-75. 
15. Inoue H, Watanabe H, Okami H, Shiraishi Y, Kimura A, Takeshita K. Handgrip strength correlates with walking in lumbar spinal stenosis. Eur Spine J. 2020;29(9):2198-204. http://dx.doi.org/10.1007/s00586020-06525-1. PMid:32651633.

16. Muren MA, Hütler M, Hooper J. Functional capacity and healthrelated quality of life in individuals post stroke. Top Stroke Rehabil. 2008;15(1):51-8. http://dx.doi.org/10.1310/tsr1501-51. PMid:18250074.

17. Schmidt RT, Toews JV. Grip strength as measured by the Jamar dynamometer. Arch Phys Med Rehabil. 1970;51(6):321-7. PMid:5423802.

18. Hudak PL, Amadio PC, Bombardier C, Beaton D, Cole D, Davis A, et al. Development of an upper extremity outcome measure: the DASH (disabilities of the arm, shoulder and hand). Am J Ind Med. 1996;29(6):602-8. http://dx.doi.org/10.1002/(SICI)10970274(199606)29:6<602::AID-AJIM4>3.0.CO;2-L. PMid:8773720.

19. Margit AM, Resteghini C, Feys P, Lamers I. An overview of systematic reviews on upper extremity outcome measuers after stroke. BMC Neurol. 2015;15:29

20. Stricker M, Hinde D, Rolland A, Salzman N, Watson A, Almonroeder TG. Quantifying step length using two-dimensional video in individuals with Parkinson's disease. Physiother Theory Pract. 2021;37(1):252-5. PMid:30896266.

21. Patterson KK, Gage WH, Brooks D, Black SE, McIlroy WE. Evaluation of gait symmetry after stroke: a comparison of current methods and recommendations for standardization. Gait Posture. 2010;31(2):241-6. http://dx.doi.org/10.1016/j.gaitpost.2009.10.014. PMid:19932621.

22. Liaw LJ, Hsieh CL, Lo SK, Chen HM, Lee S, Lin JH. The relative and absolute reliability of two balance performance measures in chronic stroke patients. Disabil Rehabil. 2008;30(9):656-61. http://dx.doi. org/10.1080/09638280701400698. PMid:17852318.

23. Macellari V, Giacomozzi C, Saggini R. Spatial-temporal parameters of gait: reference data and a statistical method for normality assessment. Gait Posture. 1999;10(2):171-81. http://dx.doi.org/10.1016/S09666362(99)00021-1. PMid:10502651.

24. Akoglu H. User's guide to correlation coefficients. Turk J Emerg Med. 2018;18(3):91-3. http://dx.doi.org/10.1016/j.tjem.2018.08.001. PMid:30191186.

25. English C, McLennan H, Thoirs K, Coates A, Bernhardt J. Loss of skeletal muscle mass after stroke: a systematic review. Int J Stroke. 2010;5(5):395-402. http://dx.doi.org/10.1111/j.17474949.2010.00467.x. PMid:20854624.

26. Zhang Q, Lu H, Pan S, Lin Y, Zhou K, Wang L. 6MWT performance and its correlations with $\mathrm{VO}(2)$ and handgrip strength in homedwelling mid-aged and older chinese. Int J Environ Res Public Health. 2017;14(5):473. http://dx.doi.org/10.3390/ijerph14050473.

27. Park JG, Lee KW, Kim SB, Lee JH, Kim YH. Effect of decreased skeletal muscle index and hand grip strength on functional recovery in subacute ambulatory stroke patients. Ann Rehabil Med. 2019;43(5):535-43. http://dx.doi.org/10.5535/arm.2019.43.5.535. PMid:31693843.

28. Shin HI, Kim DK, Seo KM, Kang SH, Lee SY, Son S. Relation between respiratory muscle strength and skeletal muscle mass and hand grip strength in the healthy elderly. Ann Rehabil Med. 2017;41(4):686-92. http://dx.doi.org/10.5535/arm.2017.41.4.686. PMid:28971054.

29. Chen G, Patten C, Kothari DH, Zajac FE. Gait differences between individuals with post-stroke hemiparesis and non-disabled controls at matched speeds. Gait Posture. 2005;22(1):51-6. http://dx.doi. org/10.1016/j.gaitpost.2004.06.009. PMid:15996592.

30. Souissi H, Zory R, Boudarham J, Pradon D, Roche N, Gerus P. Muscle force strategies for poststroke hemiparetic patients during gait. Top Stroke Rehabil. 2019;26(1):58-65. http://dx.doi.org/10.1080/107493 57.2018.1536023. PMid:30354914.

31. Molla RY, Sadeghi H, Farahmand F, Azarbayjani MA. Effect of excessive arm swing on speed and cadence of walking. J Men's Health. 2020;4(1):e5.

32. Takahashi J, Nishiyama T, Matsushima Y. Does grip strength on the unaffected side of patients with hemiparetic stroke reflect the strength of other ipsilateral muscles? J Phys Ther Sci. 2017;29(1):64-6. http:// dx.doi.org/10.1589/jpts.29.64. PMid:28210040.

33. Patterson KK, Gage WH, Brooks D, Black SE, Mcllroy WE. Changes in gait symmetry and velocity after stroke: a cross sectional study from weeks to years after stroke. Neurorehabil Neural Repair. 2010;24(9):783-90. http://dx.doi.org/10.1177/1545968310372091. PMid:20841442.

34. Dehno NS, Sarvestani FK, Shariat A, Jaberzadeh S. Relationship of hand strength with paretic upper extremity function and activities of daily living performance in patients with subacute stroke. Physiother Pract Res. 2020;41(1):69-77. http://dx.doi.org/10.3233/PPR-190147.

35. Izawa KP, Kasahara Y, Hiraki K, Hirano Y, Oka K, Watanabe S. Longitudinal changes of handgrip, knee extensor muscle strength, and the disability of the arm, shoulder and hand score in cardiac patients during phase ii cardiac rehabilitation. Diseases. 2019;7(1):32. http:// dx.doi.org/10.3390/diseases7010032. PMid:30917524.

36. Patterson MR, Whelan D, Reginatto B, Caprani N, Walsh L, Smeaton AF, et al. Does external walking environment affect gait patterns? Conf Proc IEEE Eng Med Biol Soc. 2014;2014:2981-4. http://dx.doi. org/10.1109/EMBC.2014.6944249. PMid:25570617.

37. Liu J, Drutz C, Kumar R, McVicar L, Weinberger R, Brooks D, et al. Use of the six-minute walk test poststroke: is there a practice effect? Arch Phys Med Rehabil. 2008;89(9):1686-92. http://dx.doi. org/10.1016/j.apmr.2008.02.026. PMid:18760152.

38. Dalton E, Lannin NA, Laver K, Ross L, Ashford S, McCluskey A, et al. Validity, reliability and ease of use of the disabilities of arm, shoulder and hand questionnaire in adults following stroke. Disabil Rehabil. 2017;39(24):2504-11. http://dx.doi.org/10.1080/09638288.2016.122 9364. PMid:27767374.

39. Baker K, Barrett L, Playford ED, Aspden T, Riazi A, Hobart J. Measuring arm function early after stroke: is the DASH good enough? J Neurol Neurosurg Psychiatry. 2016;87(6):604-10. http://dx.doi. org/10.1136/jnnp-2015-310557. PMid:26180212.

40. van der Kooi AL, Snijder MB, Peters RJ, van Valkengoed IG. The association of handgrip strength and type 2 diabetes mellitus in six ethnic groups: an analysis of the HELIUS study. PLoS One. 2015;10(9):e0137739. http://dx.doi.org/10.1371/journal. pone.0137739. PMid:26368020.

41. Bertoni AG, Bancks M, Crago, L, Chen H, Barr RG, Smith B, Shah, SJ. Abstract P151: race/ethnic differences in six minute walk distance among older adults: the multi-ethnic study of atherosclerosis. In: AHA, editor. AHA Epidemiology and Prevention-Lifestyle and Cardiometabolic Health 2020 Scientific Sessions; 2020 Mar 2; Arizona,: American Heart Association; 2020. (Circulation; vol. 141, suppl. 1). 


\section{Author contributions}

AJ: conceptualization of the study; data acquisition, analysis and/or interpretation; writing, revising and editing the manuscript; JF: data acquisition, analysis and interpretation; writing, revising and/or editing the manuscript; RB, JT, RB, LV, DHEJV: conceptualization of the study; data acquisition, supervision; analysis and interpretation; writing, revising and/or editing the manuscript.

\section{Author information}

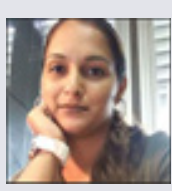

Ameerani Jarbandhan

Graduated in Physiotherapy, Anton de Kom University of Suriname,

Suriname

$\mathrm{PhD}$ in Biomedical Sciences, KU Leuven, Belgium

Lecturer, Department of Anatomy, Anton de Kom University of Suriname, Suriname

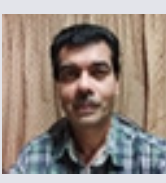

Jerry Toelsie

Graduated in Medicine (MD), Anton de Kom Universiteit van

Suriname, Suriname

$\mathrm{PhD}$ in Medical Science, Universiteit Hasselt, Belgium

Associate Professor, Department of Physiology, Faculty of Medical Science, Anton de Kom Universiteit an Suriname, Suriname

Robbert Bipat

Graduated in Medicine (MD), Anton de Kom Universiteit van

Suriname, Suriname

$\mathrm{PhD}$ in Medical Science, Universiteit Hasselt, Belgium

Associate Professor, Department of Physiology, Faculty of Medical Science, Anton de Kom Universiteit

van Suriname, Suriname

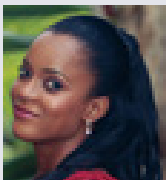

Jeannine Freedrik

Graduated in Physiotherapy, Anton de Kom University, Suriname,

Suriname

Master of Science in Physical Therapy

Physical Therapist at the Diakonessenhuis Paramaribo, Suriname

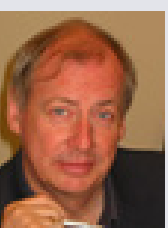

Luc Vanhees

Graduated in Physiotherapy and Clinical physiology, KU Leuven,

Belgium

PhD in Rehabilitation Sciences, KU Leuven, Belgium

Professor at University of Applied Sciences Utrecht, the Netherlands

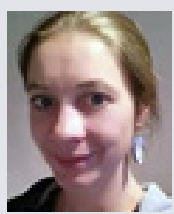

Roselien Buys

Graduated in Sport Sciences

$\mathrm{PhD}$ in Biomedical Sciences

Post-doctoral researcher at KU Leuven, Belgium

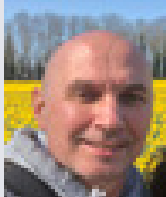

DirkJan H.E.J. Veeger

Graduated in Muskuloskeletal Mechanics at the Biomedical

Engineering Department

Phd in Biomechanics of Wheelchair Propulsion

Professor at Delft University of Technology

Director of Education of the Faculty of Mechanical, Maritime and Materials Engineering 